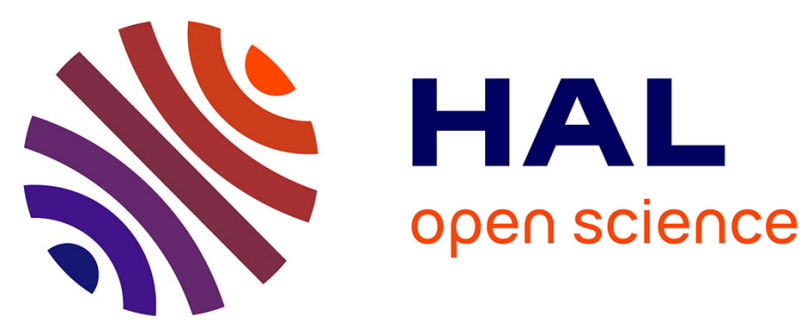

\title{
A computational damage mechanics approach for laminates: Identification and comparison with experimental results
}

Pierre Ladevèze, Olivier Allix, Laurent Gornet, David Lévêque, Lionel Perret

\section{- To cite this version:}

Pierre Ladevèze, Olivier Allix, Laurent Gornet, David Lévêque, Lionel Perret. A computational damage mechanics approach for laminates: Identification and comparison with experimental results. Studies in Applied Mechanics, 1998, pp.481-500. 10.1016/S0922-5382(98)80059-7 . hal-01759138

\author{
HAL Id: hal-01759138 \\ https://hal.science/hal-01759138
}

Submitted on 22 Oct 2019

HAL is a multi-disciplinary open access archive for the deposit and dissemination of scientific research documents, whether they are published or not. The documents may come from teaching and research institutions in France or abroad, or from public or private research centers.
L'archive ouverte pluridisciplinaire HAL, est destinée au dépôt et à la diffusion de documents scientifiques de niveau recherche, publiés ou non, émanant des établissements d'enseignement et de recherche français ou étrangers, des laboratoires publics ou privés. 


\title{
A Computational Damage Mechanics Approach for Laminates: Identification and Comparison with Experimental Results
}

\author{
P. Ladevèze $a$, O. Allix ${ }^{a}$, L. Gornet $^{\mathrm{a}}, \mathrm{D}$. Lévêque ${ }^{\mathrm{a}}$ and L. Perret ${ }^{\mathrm{b}}$ \\ a Laboratoire de Mécanique et Technologie, E.N.S. de Cachan/C.N.R.S./ Université Paris 6, \\ 61, avenue du Président Wilson, 94235 Cachan Cedex - France. \\ b Centre National d'Études Spatiales (CNES) / Toulouse, 18, Av. Édouard Belin - 31055 \\ Toulouse Cedex - France.
}

The present study concerns finite element predictions of carbon-fiber/epoxy-resin composite coupon delamination tests up to fracture. For these predictions, a previously-defined damage mesomodel of composite laminates is used and implemented in a tridimensional F.E. code. This F.E. software includes the interlaminar interfacial deterioration as well as the main inner layer damage mechanisms. This code is able to predict at any time and at any point the "intensities" of the different damage mechanisms up to fracture. However herein, attention is being focused on the identification and comparison of F.E. predictions with M55J/M18 carbon/epoxy experimental results obtained from the AEROSPATIALE company.

\section{INTRODUCTION}

An initial step, which has been achieved in other studies, is to define what we call a laminate mesomodel. At the mesoscale, characterized by the thickness of the ply, the laminated structure is described as a stacking sequence of homogeneous layers throughout the thickness and interlaminar interfaces. The main damage mechanisms are described as: fiber breaking, matrix micro-cracking and adjacent layers debonding [1-3]. The single-layer model includes both damage and inelasticity. The interlaminar interface is defined as a two-dimensional mechanical model which ensures traction and displacement transfer from on ply to another. Its mechanical behavior depends on the angle between the fibers of two adjacent layers. 
It is well-known that fracture simulation using a continuum damage model leads to severe theoretical and numerical difficulties. A second step which has also been achieved, is to overcome these difficulties. For laminates and, more generally, for composites, we propose the concept of the mesomodel: the state of damage is uniform within each meso-constituent. For laminates, it is uniform throughout the thickness of each single layer; as a complement, continuum damage models with delay effects are introduced.

Two models have to be identified: the single layer model and the interface model [4-7,911,13,16]. The appropriate tests used consist of: tension, bending, delamination. Each composite specimen, which contains several layers and interfaces, is computed in order to derive the material quantities intrinsic to the single layer or to the interlaminar interface [9-11]. The proposed procedure is rather simple and has been applied to various materials. Various comparisons with experimental results have been performed to show the possibilities and the limits of our proposed computational damage mechanics approach for laminates. A Finite Element code, devoted to stiff stress gradients, has been developed. It's an extended version of the F.E. code Castem 2000 (C.E.A.) [8]. Several tests of delamination propagation (DCB, MMF, ENF and CLS) or of initiation (edge delamination or holed plate specimens) are considered herein.

We will pay special attention to the basic aspects of the finite element simulations of interlaminar and intralaminar damages. The finite element predictions of classical Fracture Mechanics coupon tests are analyzed. In particular, the value of using a Damage Mechanics approach for initiation prediction as well as for the interpretation of standard Fracture Mechanics tests, in connection with experiments [11], is discussed.

\section{MESOMODELING CONCEPT}

Let us recall that delamination often appears as an interaction between fiber-breaking, transverse micro-cracking and the debonding of adjacent layers itself. For laminates, three different scales may easily be defined: the micro scale of the individual fiber, the meso scale associated with the thickness of the elementary ply, and the macro scale which is the structural one. Due to the small thickness of the elementary ply and to the kinematics of the deterioration inside the ply, it is both possible and worthwhile to derive a material model at the mesoscale. The one proposed in [5] is defined by two meso-constituents, a single layer and an interface (Figure 1). The interface is a mechanical surface connecting two adjacent layers and depends on the relative orientation of their fibers. 


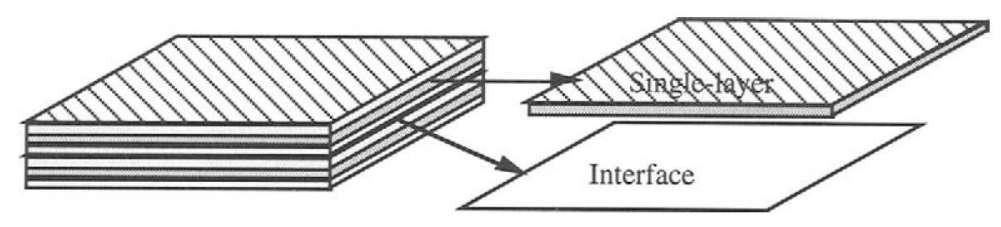

Figure 1. Laminate modeling

A mesomodel is then defined by adding another property: a uniform damage state is prescribed throughout the thickness of the elementary ply. This point plays a major role when one tries to simulate a crack with a damage model. Let us recall that in order to be able to perform a complete analysis of the delamination process in all cases, damage models with delay effects are introduced for the in-plane direction. One limitation of the proposed mesomodel is that it is able to describe only two types of macrocracks. The first type is a delamination crack within the interface, and the second type is the crack is orthogonal to the laminate with each cracked layer being completely cracked in its thickness. Let us also note that the $\left(0^{\circ}, 0^{\circ}\right)$ interface appears to be something artificial if the material is well made. Normally, such an interface need not be introduced. However, such an "artificial" interface can be introduced for describing an initial crack in a thick layer.

Let us recall that the single-layer model and its identification, including damage such as fiber-breaking and transverse micro-cracking as well as inelastic effects, were previously developed in [4-5]. In section 3, the single-layer model is detailed.

\section{SINGLE-LAYER MODELING}

The carbon-fiber/epoxy-resin material under consideration in this study has only one reinforced direction. In what follows, subscripts 1, 2 and 3 designate the fiber direction, the transverse direction inside the layer and the normal direction, respectively. An energy is proposed here to predict the damage in a laminated structure [9]. The damaged material strain energy, by splitting the energy into a "tension" energy and a "compression" energy, is written in the case of the plane stress assumption. With the transverse rigidity in compression being supposed equal to $E_{2}^{0}$, one then obtains the following energy for the damaged-layer material: 


$$
\begin{gathered}
\mathrm{E}_{\mathrm{D}}^{\mathrm{cp}}=\frac{1}{2\left(1-\mathrm{d}_{\mathrm{F}}\right)}\left[\frac{<\sigma_{11}^{>_{+}}+}{\mathrm{E}_{1}^{\mathrm{o}}}+\frac{\left.\phi\left(<-\sigma_{11}\right\rangle_{+}\right)}{\mathrm{E}_{1}^{\mathrm{o}}}-\left(\frac{v_{21}^{o}}{\mathrm{E}_{2}^{\mathrm{o}}}+\frac{v_{12}^{o}}{\mathrm{E}_{1}^{\mathrm{o}}}\right) \sigma_{11} \sigma_{22}\right] \\
+\frac{1}{2}\left[\frac{<\sigma_{22}>_{+}^{2}}{\left(1-\mathrm{d}^{\prime}\right) \mathrm{E}_{2}^{\mathrm{o}}}+\frac{<-\sigma_{22}>_{+}^{2}}{\mathrm{E}_{2}^{\mathrm{o}}}+\frac{\sigma_{12}^{2}}{(1-\mathrm{d}) \mathrm{G}_{12}^{\mathrm{o}}}\right]
\end{gathered}
$$

where $\phi$ is a material function, that takes into accout the non-linear response in compression. $\mathrm{d}_{\mathrm{F}}, \mathrm{d}$ and $\mathrm{d}^{\prime}$ are three scalar internal variables which remain constant within the thickness. They define the damage of the single layer. The forces associated with the mechanical dissipation are:

$$
\begin{aligned}
& Y_{d}=\frac{\partial}{\partial d}<<E_{D}^{e}>>\left.\right|_{\sigma: c s t}=\frac{\left.<<\sigma_{12}^{2}\right\rangle>}{2 G_{12}^{o}(1-d)^{2}} \\
& \mathrm{Y}_{\mathrm{d}^{\prime}}=\frac{\partial}{\partial \mathrm{d}^{\prime}} \ll<\mathrm{E}_{\mathrm{D}^{\mathrm{N}}}^{\mathrm{e}}>>\left.\right|_{\sigma: \mathrm{cst}}=\frac{<<<\sigma_{22}>_{+}^{2}>>}{2 \mathrm{E}_{2}^{\mathrm{o}}\left(1-\mathrm{d}^{\prime}\right)^{2}} \\
& \mathrm{Y}_{\mathrm{F}}=\frac{\partial}{\partial d_{F}}<<\mathrm{E}_{\mathrm{D}}^{\mathrm{e}}>>\left.\right|_{\sigma: \mathrm{cst}} \\
& =\frac{1}{2\left(1-d_{F}\right)^{2}}<<\frac{<\sigma_{11}>_{+}^{2}}{2 \mathrm{E}_{1}^{\mathrm{o}}}+\frac{<-\sigma_{11}>_{+}^{2}}{2 \mathrm{E}_{1}^{\mathrm{c}}}-\left(\frac{\mathrm{v}_{21}^{\mathrm{o}}}{\mathrm{E}_{2}^{\mathrm{o}}}+\frac{\mathrm{v}_{12}^{\mathrm{o}}}{\mathrm{E}_{1}^{\mathrm{o}}}\right) \sigma_{11} \sigma_{22}>>
\end{aligned}
$$

where $\langle\mathrm{X}\rangle_{+}$is the positive part of $\mathrm{X}$ and $\langle<>>$ denotes the mean value within the thickness. For static loadings, the damage evolution law can be formally written:

$\mathrm{d}_{\left.\right|_{t}}=A_{d}\left(\left.Y_{d}\right|_{\tau},\left.Y_{d^{\prime}}\right|_{\tau}, \tau \leq t\right) ;\left.d^{\prime}\right|_{t}=A_{d^{\prime}}\left(Y d_{\tau^{\prime}},\left.Y^{\prime}\right|_{\tau}, \tau \leq t\right)$

where the operators $A_{d}$ and $A_{d}$ are material characteristics. The operator $A_{d}$ is drawn for instance in Figure 2. $\mathrm{d}_{\mathrm{F}}$ corresponds to a brittle fracture mechanism. More details, in particular for the modeling of inelastic strains, can be found in $[4,7,9]$. 


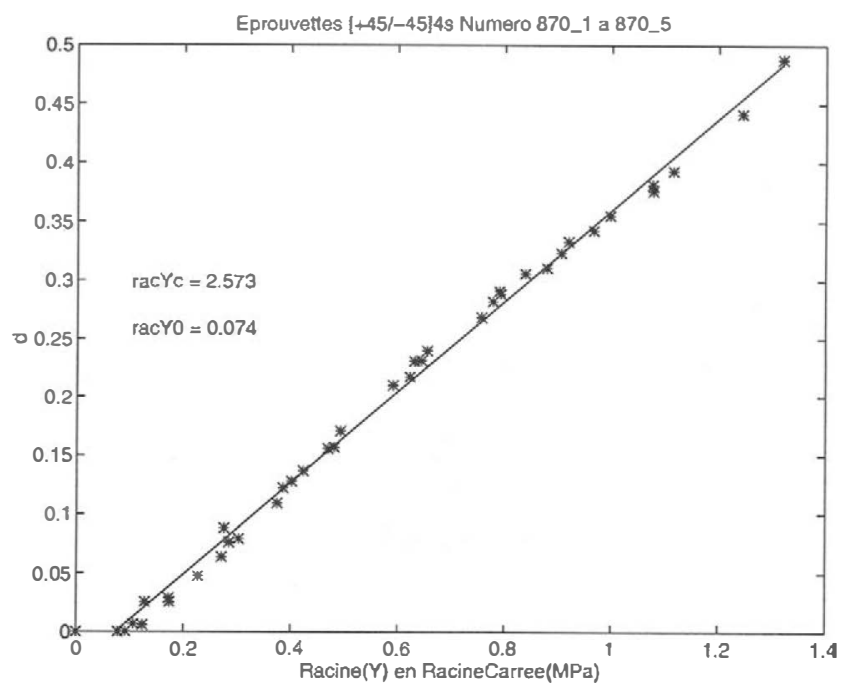

Figure 2. Shear damage evolution of the elementary ply for the M55J/M18 material.

\section{INTERLAMINAR INTERFACE MODELING}

\subsection{Damage kinematics of the interface}

The interlaminar connection is thus modeled as a two-dimensional entity which ensures stress and displacement transfers from one ply to another. The diagram leading to the definition of the interface is classical for isotropic bi-materials. The interlaminar connection can be interpreted as a ply of matrix whose thickness (denoted by e) is small compared to the inplane dimension. Therefore, the wavelength of the displacement in the normal direction $\underline{\mathrm{N} 3}$ is on the order of magnitude of the thickness, while the wavelength of the displacement fields in the plane is on the order of the in-plane directions.

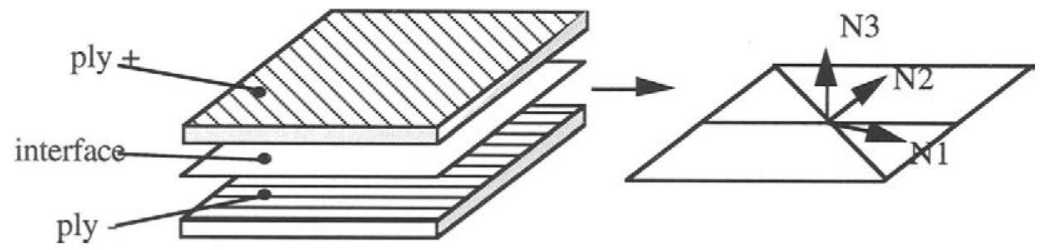

Figure 3. "Orthotropic" directions of the interface. 


$$
[\mathrm{U}]=\mathrm{U}^{+}-\mathrm{U}^{-}=[\mathrm{U}]_{1} \underline{\mathrm{N}}_{1}+[\mathrm{U}]_{2} \underline{\mathrm{N}}_{2}+[\mathrm{W}] \underline{\mathrm{N}}_{3}
$$

is the difference in displacements between the upper and lower surfaces of $\Omega$. Thus, at the first order, the strain energy of $\Omega$ is:

$$
\mathrm{E}_{\mathrm{d}}=\frac{1}{2} \int_{\Omega} \operatorname{Tr}\left[\mathrm{K} \varepsilon_{0} \varepsilon_{0}\right] \mathrm{d} \Omega \approx \frac{1}{2} \mathrm{e} \int_{\Gamma} \frac{[\mathrm{U}]^{\mathrm{T}}}{\mathrm{e}} \mathrm{H} \frac{[\mathrm{U}]}{\mathrm{e}} \mathrm{d} \Gamma
$$

where $\Gamma$ is the area of the mid-plane interface, and $\mathrm{H}$ is a $(3,3)$ symmetric matrix. Let us denote the bisectors of the fiber directions by $\left(\underline{N}_{1}, \underline{N}_{2}\right)$. They are necessarily "orthotropic" directions of the interface, since a $\left[\theta_{1}, \theta_{2}\right]$ interface is equivalent to a $\left[\theta_{2}, \theta_{1}\right]$ interface (Figure 3 ). The ideas and framework which govern the interface damage model are similar to those used for deriving the layer damage model [5],[9]. Like in the layer model, the effect of the deterioration of the interlaminar connection on its mechanical behavior is taken into account by means of internal damage variables. The different behavior in "tension" and in "compression" are distinguished by splitting the strain energy into "tension-energy " and "compressionenergy". More precisely, we use the following expression, as proposed in [10], of the energy per unit area. Thus, in the $\left(\underline{\mathbf{N}}_{1}, \underline{N}_{2}, \underline{N}_{3}\right)$ axes, the elastic strain energy of the interface may be written as follows in stress form:

$\mathrm{E}_{\mathrm{d}}=\frac{1}{2} \int_{\Gamma}\left[\frac{<-\sigma_{33}>_{+}{ }^{2}}{\mathrm{k}_{\mathrm{o}}^{3}}+\frac{<\sigma_{33}>_{+}{ }^{2}}{\mathrm{k}_{\mathrm{o}}^{3}\left(1-\mathrm{d}_{3}\right)}+\frac{\sigma_{13}{ }^{2}}{\mathrm{k}_{\mathrm{o}}^{1}\left(1-\mathrm{d}_{1}\right)}+\frac{\sigma_{23}{ }^{2}}{\mathrm{k}_{\mathrm{o}}^{2}\left(1-\mathrm{d}_{2}\right)}\right] \mathrm{d} \Gamma$

Three internal damage indicators, associated with the three Fracture Mechanics modes, are thereby introduced.

\subsection{Interfacial damage evolution laws}

These evolution laws must satisfy the Clausius-Duheim inequality. Classically, the damage forces, associated with the dissipated energy $\omega$, are introduced as follows:

$\mathrm{Y}_{\mathrm{d}_{3}}=\frac{1}{2} \frac{<\sigma_{33^{2}}>_{+}^{2}}{\mathrm{k}^{0}(1-\mathrm{d})^{2}} ; \mathrm{Y}_{\mathrm{d}_{1}}=\frac{1}{2} \frac{\sigma_{31}^{2}}{\mathrm{k}_{1}^{0}\left(1-\mathrm{d}_{1}\right)^{2}} ; \mathrm{Y}_{\mathrm{d}_{2}}=\frac{1}{2} \frac{\sigma_{32}^{2}}{\mathrm{k}_{2}^{0}\left(1-\mathrm{d}_{2}\right)^{2}}$

with: $\omega=Y_{d_{3}} \dot{d}_{3}+Y_{d_{1}} \dot{d}_{1}+Y_{d} \dot{d}_{2} \quad(\omega \geq 0)$ 
The damage evolution laws used in this study are based on the assumption that the evolution of the different damage indicators is strongly coupled and driven by a unique equivalent damage force. The following model, developed in [13], considers that the damage evolution is governed by means of an equivalent damage force of the following form:

$\underline{Y}(\mathrm{t})=\left.\sup \right|_{\tau \leq \mathrm{t}}\left[\left.\left(\mathrm{Y}_{\mathrm{d} 3}^{\alpha}+\left(\gamma_{1} \mathrm{Y}_{\mathrm{d}_{1}}\right)^{\alpha}+\left(\gamma_{2} \mathrm{Y}_{\mathrm{d}_{2}}\right)^{\alpha}\right)\right|_{\tau} ^{1 / \alpha}\right]$

where $\gamma_{1}, \gamma_{2}$ and $\alpha$ are material parameters. In terms of delamination modes, the first term is associated with the first opening mode, and the two others are associated with the second and third modes. Compared to other damage evolution laws, used for example in [5-7], an enhanced coupling model, associated with the parameter $\alpha$, is proposed. The effect herein is to be able to describe Fracture Mechanics failure loci which are quite general. A damage evolution law is then defined by the choice of a material function $\mathrm{W}$, such that:

$\mathrm{d}_{3}=\mathrm{d}_{1}=\mathrm{d}_{2}=\mathrm{W}(\underline{\mathrm{Y}})$ if $\mathrm{d}<1 ; \mathrm{d}_{3}=\mathrm{d}_{1}=\mathrm{d}_{2}=1$ otherwise

A simple case, used for application purposes, is:

$W(\underline{Y})=\left[\frac{n}{n+1} \frac{<\underline{Y}-Y_{o}>_{+}}{Y_{c^{-}}-Y_{O}}\right]^{n}$

where a critical value $Y_{c}$ and a threshold value $Y_{o}$ are introduced. High values of $n$ correspond to a brittle interface.

To summarize, the damage evolution law is defined by means of six intrinsic material parameters $\mathrm{Y}_{\mathrm{c}}, \mathrm{Y}_{\mathrm{o}}, \gamma_{1}, \gamma_{2}, \alpha$ and $\mathrm{n}$. The threshold $\mathrm{Y}_{\mathrm{o}}$ is introduced here in order to expand the possibility of describing both the initiation of a delamination crack and its propagation. As regards the initiation of a delamination crack, the significant parameters are $Y_{0}, n$ and $\alpha$. It will be shown hereafter that $Y_{c}, \gamma_{1}, \gamma_{2}$ and $\alpha$ are related to the critical damage forces.

\subsection{Identification method for interface propagation parameters}

A simple way to identify the propagation parameters is to compare the mechanical dissipation yielded by the two approaches of Damage Mechanics and Linear Elastic Fracture Mechanics. This was performed in [13], and only the results will be presented below. In the case of pure-mode situations, when the critical energy release rate reaches its stabilized value at the propagation denoted by $G_{c}^{p}$, we obtain: 
$G_{c \mathrm{I}}^{p}=Y_{c} ; \quad G_{c \mathrm{II}}^{p}=\frac{Y_{c}}{\gamma_{1}} ; \quad G_{c \mathrm{III}}^{p}=\frac{Y_{c}}{\gamma_{2}}$

For a mixed-mode loading situation, a standard LEFM model [14] is simply derived:

$$
\left(\frac{G_{\mathrm{I}}}{G_{c \mathrm{I}}^{p}}\right)^{\alpha}+\left(\frac{G_{\mathrm{II}}}{G_{c \mathrm{II}}^{p}}\right)^{\alpha}+\left(\frac{G_{\mathrm{III}}}{G_{c \mathrm{III}}^{p}}\right)^{\alpha}=1
$$

\subsection{Extension with delay effects}

In order to obtain, in all cases, a consistent model for the description of rupture, a variant of the previous damage model that introduces delay effects $[8-13,15,16]$ is applied. In quasi-static problems, the use of such damage evolution laws implicitly introduces a length scale into the governing equations of the problem and thus avoids the pathological mesh sensitivity for composite structures.

\section{FRACTURE MECHANICS TESTS}

\subsection{Introduction}

The aim of this section is to present the classical Fracture Mechanics tests which have been chosen to identify the interface damage model. In a second step, these examples will be predicted with the help of our F.E. code and then compared with experimental results. The tests conducted in this work are the pure-mode I DCB (Double-Cantilever Beam) Test [17], the pure-mode II ENF (End-Notched Flexure) test [18], and two mixed-mode tests: the MMF (Mixed-Mode Flexure) test and the CLS (Cracked-Lap Shear) test [19] (Figure 4). These tests were conducted on an INSTRON testing machine at ambient temperature, and the displacement rate loading was set at $2 \mathrm{~mm} \mathrm{~min}^{-1}$ in the DCB and CLS tests and at $1 \mathrm{~mm} \mathrm{~min}^{-1}$ in the ENF and MMF tests. The F.E. predictions were conducted on HP 735 machines.

The D.C.B test is probably encountered the most often in the literature. In this mode I test, the links between Linear Elastic Fracture Mechanics and Damage allow identifying the $Y_{c}$ damage model parameter. The E.N.F test is used to obtain the critical energy release rate in mode II. Using both mode I and mode II experimental results, the links between Linear Elastic Fracture Mechanics and Damage allow identifying the $\gamma_{1}$ damage model parameter. The hypothesis $\left(\gamma_{1}=\gamma_{2}\right)$ is made without any further experimental information on mode III. In the M.M.F test, a mixed-mode critical energy release rate is obtained. In this mixed-mode test, 
mode I is dominant. The evolution of the damageable area is refined. Each specimen tested is a $\left[(+\theta /-\theta)_{4 s} /(-\theta /+\theta)_{4 s}\right]$ laminate with $\theta=0^{\circ}, 22.5^{\circ}$ or $45^{\circ}$, according to the three kinds of $\pm \theta$ interlaminar interfaces investigated. The stacking sequence is equilibrated and symmetric in each arm of the beam in order to suppress any bending/twisting-membrane coupling effect. Such tests are usually analyzed by means of Linear Elastic Fracture Mechanics (LEFM). Nevertheless, in the case of carbon-epoxy laminates, the main assumptions of LEFM are not always satisfied even in the simple case of a D.C.B. specimen. This is true, in particular, in the case of: non-unidirectional stacking sequences and R-curve-like phenomena. In the former case, inner layer damage mechanisms may be activated; they lead to an apparent energy release rate different from the local interfacial one. In this case, a damage analysis of the layers and interfaces should be performed [11].

a)

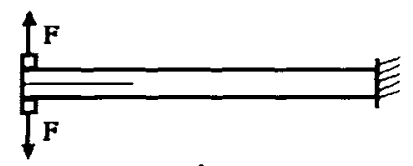

b)

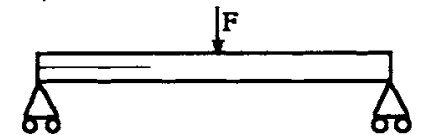

c)

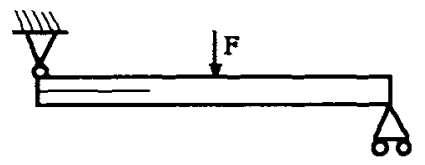

DCB test pure mode I

ENF test pure mode II

MMF test $57 \%$ mode I

CLS test

$20 \%$ mode I

Figure 4. Standard Fracture Mechanics tests.

\subsection{Identification of the damageable interface propagation parameters}

From the corrected critical energy release rates at propagation (Figure 5) [11] and from the relationships existing between Fracture Mechanics and Damage Mechanics (8), we deduce the values of the critical energies $Y_{c}$ and the coupling coefficient $\gamma_{1}$. Without any further information on mode III interlaminar fracture, let us recall that we can choose $\gamma_{2}=\gamma_{1}$, which is justified at least for a $\pm 45^{\circ}$ interface. The identification results are reported in Table 1 . For each kind of interface, the parameter $\alpha$, which governs the shape of the failure locus in the 
mixed-mode (9), is identified in the normalized mode I/mode II plane (Figure 6). It is observed that $\alpha$ is always greater than 1 , and we can choose the same parameter $\alpha$ for the two $\pm \theta$ interfaces $\left(\theta \neq 0^{\circ}\right)$.

Table 1. Interface model parameters.

\begin{tabular}{llll}
\hline Interface & $Y_{c}\left(\mathrm{~N} \mathrm{~mm}^{-1}\right)$ & $\gamma_{1}$ & $\alpha$ \\
\hline $0^{\circ} / 0^{\circ}$ & $0.113 \pm 0.007$ & $0.37 \pm 0.15$ & 1.59 \\
$\pm 22.5^{\circ}$ & $0.167 \pm 0.013$ & $0.36 \pm 0.17$ & 1.12 \\
$\pm 45^{\circ}$ & $0.192 \pm 0.014$ & $0.44 \pm 0.16$ & 1.19 \\
\hline
\end{tabular}

With the $\pm \theta$ interfaces, the dissipative phenomena inside the layers are not insignificant in particular for the case $\left(\theta= \pm 45^{\circ}\right)$, and thus a critical damage force may not be entirely attributed to the delamination process. In fact, by introducing the dissipation inside the layer it is possible to clearly identify the intrinsic damage interface parameters [11]. Let us note that the interface parameters seem to be independent of $\theta$ for all $\pm \theta$ interfaces with $\theta \neq 0^{\circ}$. Let us also note that the $\left(0^{\circ} / 0^{\circ}\right)$ interface appears to be something artificial. However, such an "artificial" interface can be introduced, for example, to describe an initial crack in a thick layer.

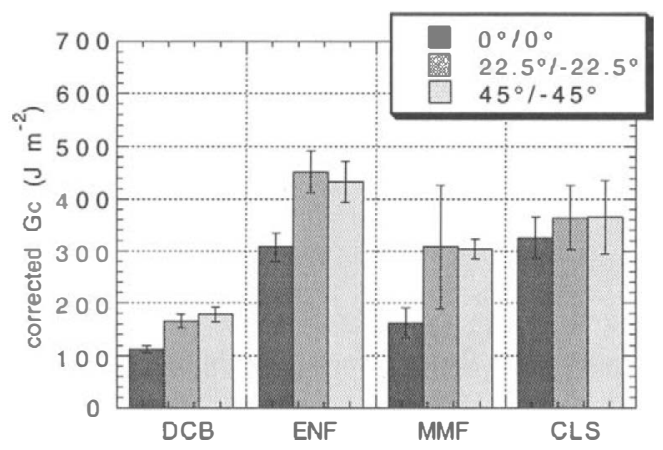

Figure 5. Critical energy release rates at propagation. 


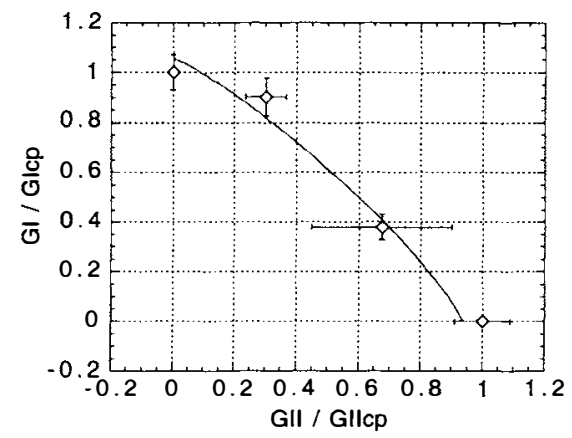

Figure 6. Identification of $\alpha$ for the $\pm 45^{\circ}$ interface.

\subsection{Simulation of classical Fracture Mechanics tests}

Tridimensional F.E. predictions are conducted, with the shape of the delaminaton front also being predicted. The tests of crack propagation in interlaminar fracture specimens are usually conducted on beam specimens with an initiated crack at the studied interface. Our specimens are $300 \mathrm{~mm}$ long and $20 \mathrm{~mm}$ wide. The mean thickness of a single ply is on the order of 0.1 $\mathrm{mm}$, and one element in the thickness is chosen for the prediction. An anti-adhesive film 40 $\mathrm{mm}$ long and $25 \mu \mathrm{m}$ thick is inserted at the mid-plane in order to initiate cracking. From a computational point of view, an interface of zero stiffness rigidity is used, in combination with unilateral contact conditions, in order to model the initial crack (anti-adhesive film) in the F.E. predictions.

The evolution of the damaged area is then refined for all test predictions. Experimental results and finite element predicted values exhibit good correlation (Figures 7-10). In particular, the lengths of the debonding area are found to be close. 


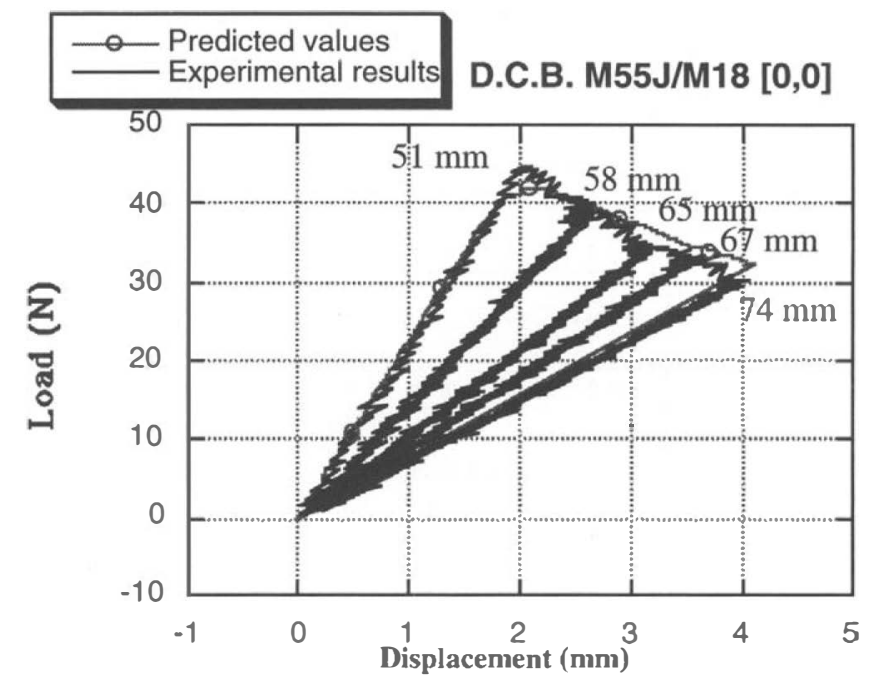

Figure 7. Prediction of a D.C.B. test. Comparison between experimental results and predicted values. The initial crack closure is $a=50 \mathrm{~mm}$. The evolution of the crack length at the end of the test is $23 \mathrm{~mm}$.

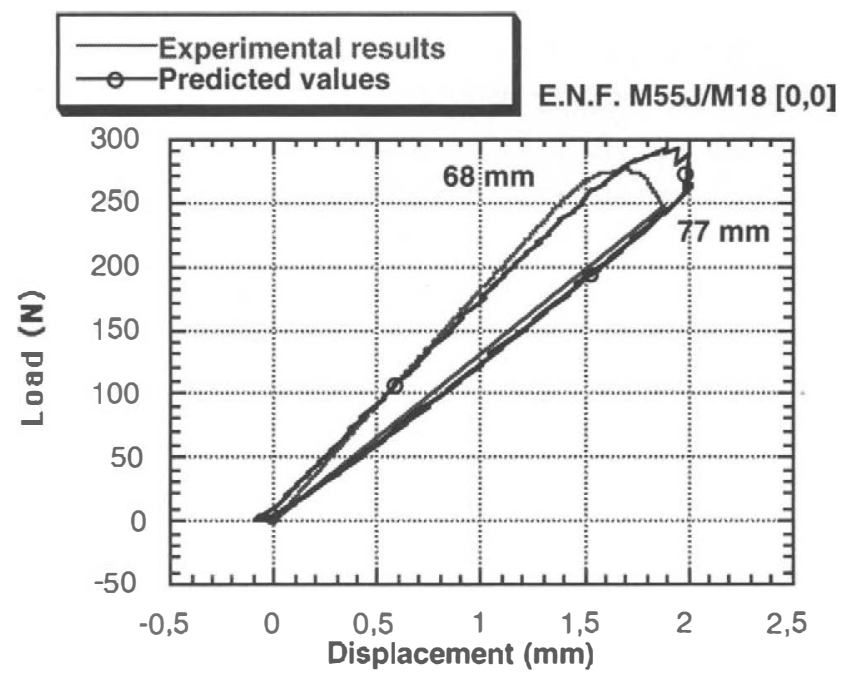

Figure 8. Prediction of an E.N.F. test. Comparison between experimental results and predicted values. The initial crack closure is $a=68 \mathrm{~mm}$. The evolution of the crack length at the end of the test is $77 \mathrm{~mm}$. 


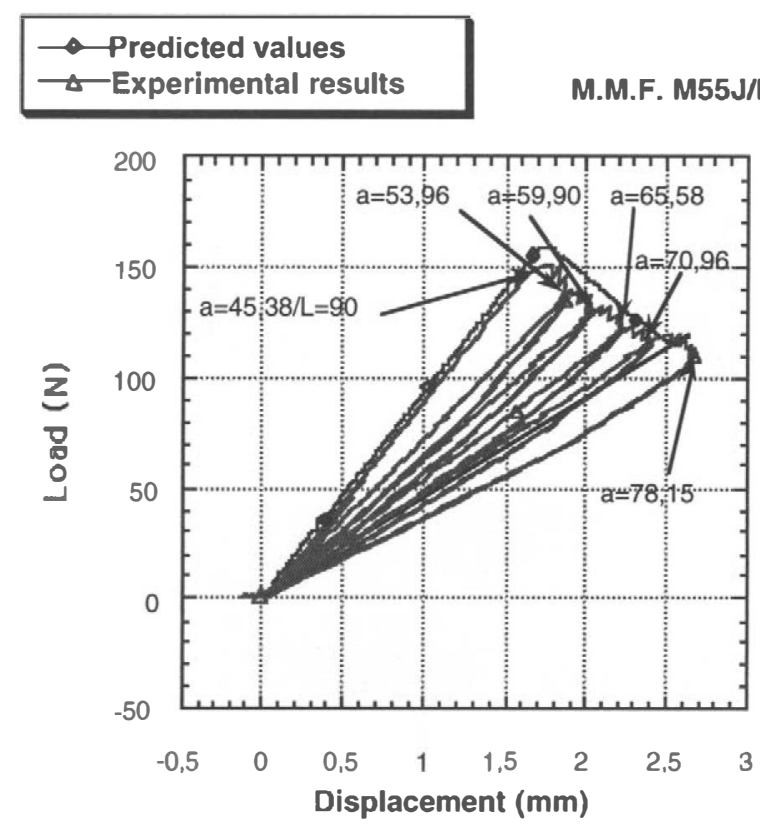

Figure 9. Prediction of an M.M.F. test. Comparison between experimental results and predicted values. The initial crack closure is $a=45 \mathrm{~mm}$, the crack length at the end of the test is $32.77 \mathrm{~mm}$.

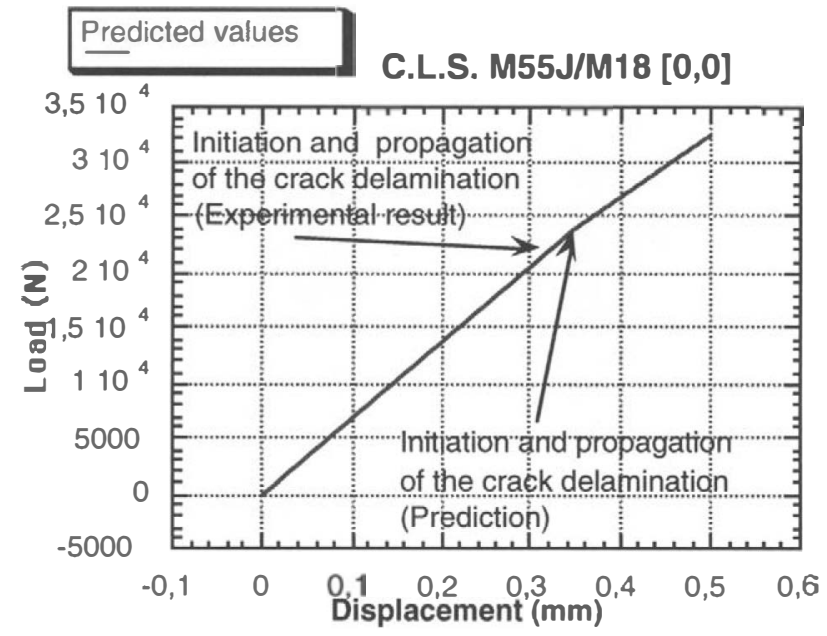

Figure 10. C.L.S. test: comparison of the initiation of the delamination crack between experimental results and predicted values. 
After each Fracture Mechanics test, the experimental delamination shape of the test specimen is highlighted by an X-ray photograph. For the unidirectional M55J/M18 material, the X-ray shape is shown in Figure 11 for the D.C.B., E.N.F., M.M.F. and C.L.S. tests. The delamination front is not straight in the width direction of the test specimens. Near the edge, there is curvature of the delamination front in all tests. In the case of the C.L.S. test, this shape is not symmetric. The computed shape of the delamination area is shown for the D.C.B. test in Figure 12. It should be noted that the curvature of the delamination front is greater for tests conducted with the M55J/M18 material with $\theta$ angle values other than 0 degrees.

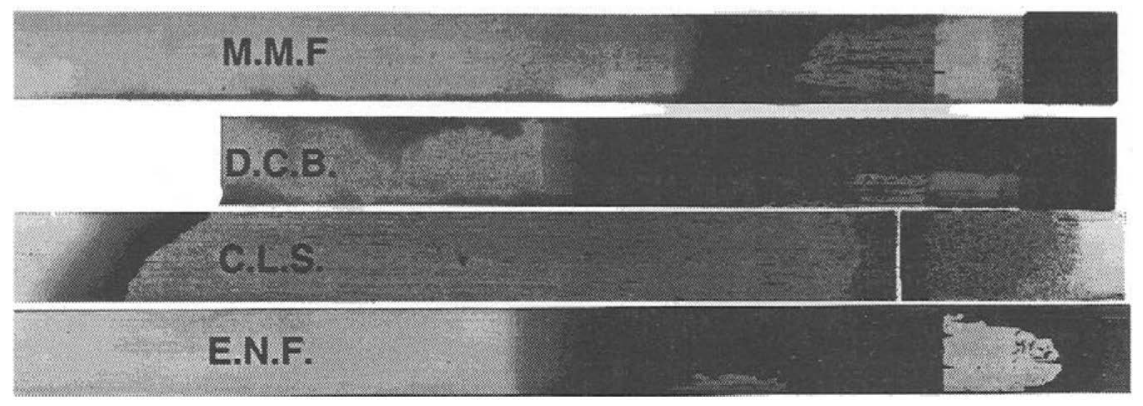

Figure 11. X-ray delamination shape photograph in the unidirectional material case.

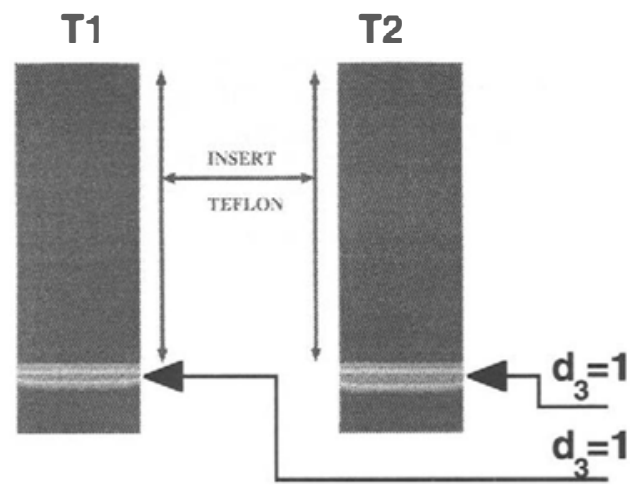

Figure 12. Prediction of the delamination front in the D.C.B. test. 


\section{INITIATION PREDICTION}

The study of the initiation of a delamination crack is often investigated by means of Edge Delamination Tension specimens [20]. In this case, Fracture Mechanics is not well adapted. In addition, delamination, especially at its onset, appears to result from an intricate interaction between inner layer damage mechanisms and the deterioration of the interlaminar interface itself [3]. Under such conditions, it seems adequate to use the previously-defined mesomodel for the layer and the interface.

In order to emphasize the value of the Damage Mechanics of Interface in the prediction of initiation, let us consider the case where damage phenomena are located in both layers and interfaces. An EDT specimen under tension was simulated. In such a case the numerical problem is set in a strip perpendicular to the edge. This type of problem has been studied in a similar way in $[6,21]$. The simulations are compared with experimental results in the case of a $\left[0_{3}, \pm 45_{2}, 90\right]_{\mathrm{s}} \mathrm{M} 55 \mathrm{~J} / \mathrm{M} 18$ material specimen. Delamination occurs at the mid-plane interface. The values of the longitudinal strain at the onset of delamination are compared. This example shows the necessity of including all the damage mechanisms into the delamination analysis even for quite simple specimens. The edge is straight and the problem to solve can be set up as a generalized plain strain problem in a strip perpendicular to the edge. In the previous test, the delamination starts on the $0 \% 0^{\circ}$ interface and after this initiation point, the load can still increase, with the maximum value of the applied tension load being around three times the initiation load. Without taking the inner layer mechanisms into account in our Finite Element Analysis, the initiation and maximum load coincide. Introducing the inner damage mechanisms (namely, the transverse and shear microcracking), the delamination propagation then becomes stable under increasing tension up to the fiber rupture of the $0^{\circ}$ plies [22]. Figure 13 depicts the state of damage before the final failure of the specimen. The comparison between the predicted values and the experimental results is quite encouraging, and the location of the onset of delamination was correctly predicted (Figure 14). 


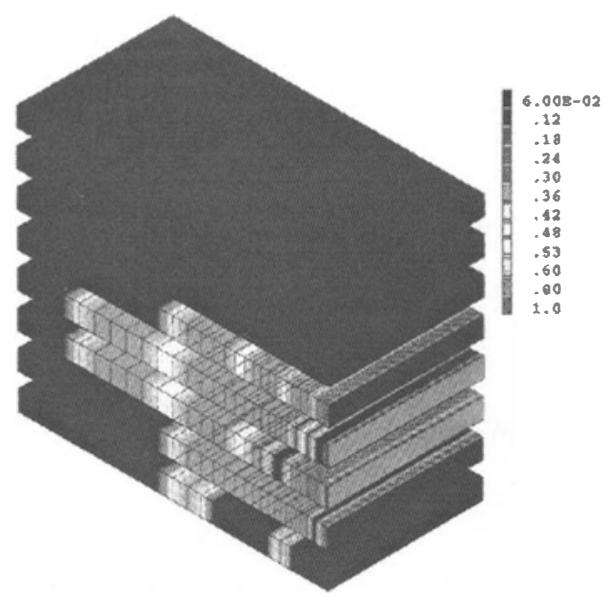

Figure 13. The laminate is a M55J/M18 $\left[0_{3}, \pm 45_{2}, 90\right]_{s y m}$ stacking sequence. The F.E. damage prediction of the quarter-section represents shear failure in the $\pm 45^{\circ}$ layers.

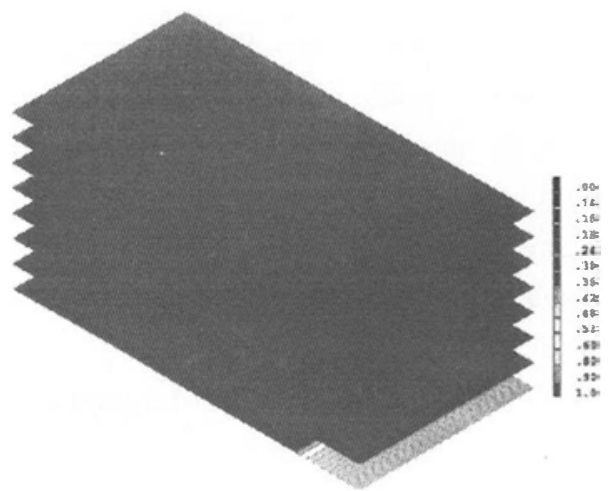

Figure 14. A crack first appears in the central interface (quarter of interface).

\section{HOLED PLATE IN TENSION}

Let us consider the structural computation example defined in Figure 15. It is a holed plate $\left[+22.5^{\circ},-22.5^{\circ}\right]_{s}$ subjected to tension. The loading history is shown in Figure 16. At any point and at any time, the code is able to yield the "intensity" of the various damage mechanisms up until the ultimate fracture. The main damage mechanism herein is delamination, i.e. the deterioration of the $\left(22.5^{\circ} /-22.5^{\circ}\right)$ interface. Figure 17 shows the value of 
the damage variable " $d_{3}$ " at times $T_{1}$ and $T_{2}$. The increase in the delaminated area is very significant. The layer's damage mechanisms are weakly excited (Figure 18).

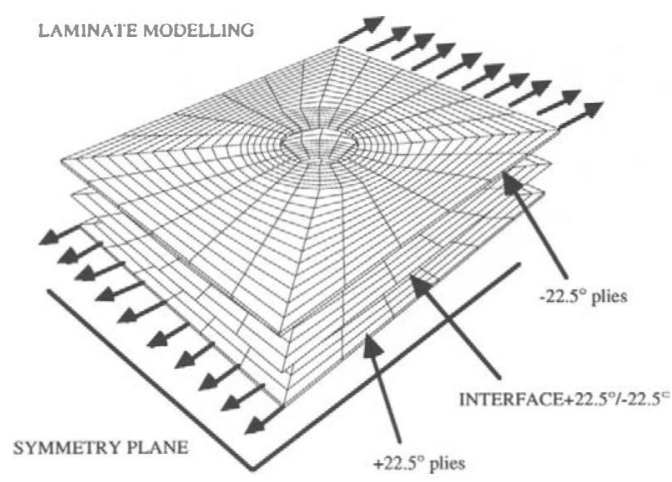

Figure 15. A structural computation example.

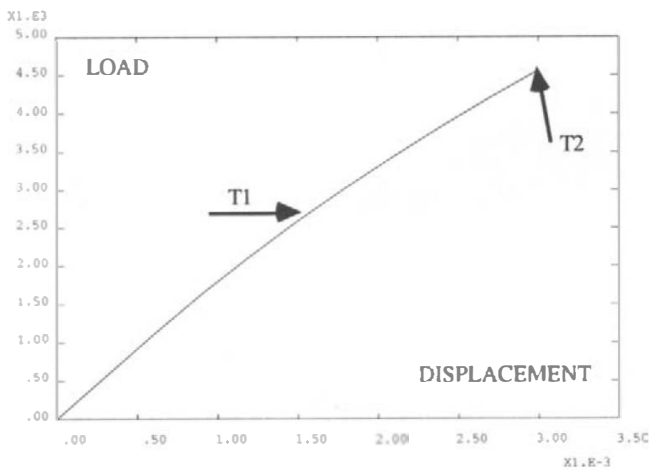

Figure 16. Loading history. 

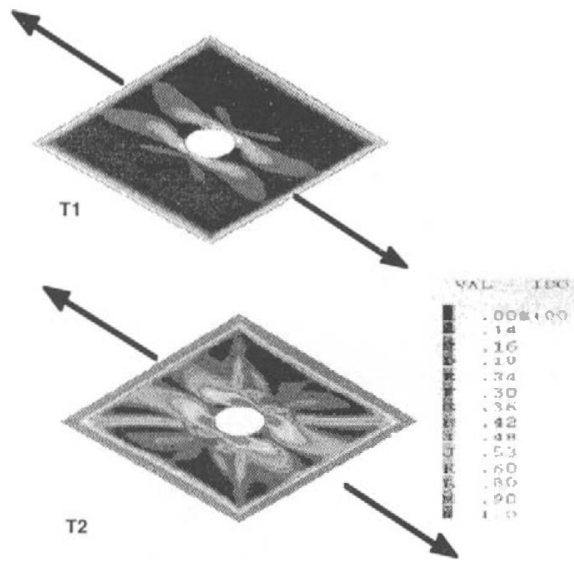

Figure 17. Damage variable $d_{3}$ of the $\left(22.5^{\circ} /-22.5^{\circ}\right)$ interface at times $T_{1}$ and $T_{2}$.

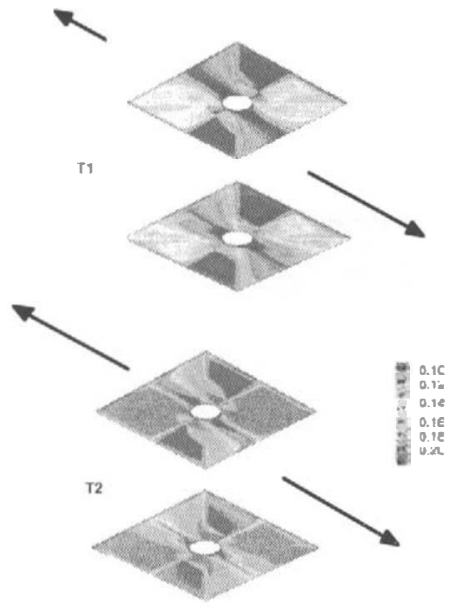

Figure 18. Damage variable d of the layers at times $\mathrm{T}_{1}$ and $\mathrm{T}_{2}$. 


\section{CONCLUSIONS}

A mesomodel of laminate structure has been built and identified for various composites. Resistance to delamination can be characterized by a few material parameters. Comparisons with experimental results proved to be very satisfactory.

However, calculations performed with such a mesomodel lead to very large computational times. A present challenge is to develop a more effective computational strategy and, in particular, to use parallel computers.

\section{REFERENCES}

1. A.L. Highsmith, and K.L.Reifsnider, Stiffness reduction mechanism in composite material, In: ASTM-STP 775, Damage in Composite Materials, A.S.T.M., pp.103-117, 1982.

2. R. Talreja, Transverse cracking and stiffness reduction in composite laminates, Journal of Composite Materials, vol.19, pp. 355-375, 1985.

3. Whithney, J.M. Experimental characterization of delamination fracture. In: Interlaminar response of composite materials, Comp.Mat. Series, 5, Pagano, N. J. Ed, 111-239, 1989.

4. P. Ladevèze, Sur la Mécanique de l'Endommagement des composites. In: Comptes rendus des JNC 5, C. Bathias \& D. Menkès Eds, Pluralis Publication, Paris, pp. 667$683,1986$.

5. P. Ladevèze, Towards a Fracture Theory, Proceedings of the Third International Conference on Computational Plasticity Part II, D.R.J. Owen, E. Onate, E. Hinton Ed, Pineridge Press, Cambridge U.K., 1992, pp. 1369-1400.

6. Daudeville L.and P. Ladevèze, A Damage Mechanics Tool for Laminate Delamination", Journal of Composite Structures $n^{\circ} 25,1993$, pp. 547-555.

7. P. Ladevèze, A damage computational method for composite structures, J. Computer and Structure, 44 (1/2), pp. 79-87, 1992.

8. Verpeaux P., Charras T. et Millard A. Castem 2000: Une approche moderne du calcul de structures, JM Fouet, P Ladeveze, R Ohayon, 2, 1988, pp. 261-227.

9. P. Ladevèze and E. Le Dantec, Damage modeling of the elementary ply for laminated composites, Composite Science and Technology, 43-3, pp.257-267, 1992. 
10. O. Allix, O. and P. Ladevèze, Interlaminar interface modelling for the prediction of laminate delamination, Composite Structures, 22, pp. 235-242, 1992.

11. Allix O., Ladevèze P., Lévêque D., Perret L. (1997) "Identification and validation of an interface damage model for delamination prediction" Computational Plasticity, Eds Owen D.R.J., Oñate E. \& Hinton E., Barcelone, pp. 1139-1147.

12. Beer, G., 1985, An isoparametric joint/interface element for finite element analysis, Int.J. for numer. methods eng., 21 , pp. 585-600.

13. O. Allix, A. Corigliano and P. Ladevèze, Damage analysis of interlaminar Fracture specimens, Composite Sructures. 31, 1995, pp. 61-74.

14. Bathias, C. 1995. Une revue des méthodes de caractérisation du délaminage des matériaux composites. Journée AMAC/CSMA "Délaminage: bilan et perspectives", $\mathrm{O}$. Allix \& M.L. Benzeggagh Eds, Cachan, may 1995.

15. Albertsen, H., J. Ivens, P. Peters, M. Wevers \& I. Verpoest, 1995, Interlaminar fracture toughness of CFRP influenced by fibre surface treatment: Part 1: Experimental results, Comp. Sc. and Tech. 54, pp. 133-145.

16. Ladevèze, $\mathrm{P} ., 1995, \mathrm{~A}$ damage computational approach for composites: Basic aspects and micromechanical relations, Computational Mechanics, 17, pp. 142-150, 1995.

17. De Charentenay, F.-X., J.M. Harry, Y.J. Prel, \& M.L Benzeggagh, 1984. Characterizing the Effect of Delamination Defect by Mode I Delamination Test. Effect of Defects in Composite Materials, ASTM STP 836, pp. 84-103.

18. Davis P., 1990. Measurement of GIc and GIIc in Carbon/Epoxy Composites, Comp. Sci. \& Technol., 39 , pp. 193-205.

19. Russell, A.J. \& K.N. Street 1985. Moisture and Temperature Effects on the MixedMode Delamination Fracture of Unidirectional Graphite/Epoxy, Delamination and Debonding of Materials, ASTM STP 876, W.S. Johnson, Eds., Philadelphia, pp. 349370 .

20. T. K. O'Brien, Characterisation of Delamination Onset and Growth in a Composite Laminate. In: Damage in Composite Materials, Reifsnider K.L. Eds., ASTM-STP 775, 140-167, 1982.

21. J. C. Schellekens and R. De Borst, A non-linear finite element approach for the analysis of mode I-free edge delamination in composites, Int. Journal Solids Structures, Vol. 309, 1239-53, 1993.

22. Gornet, L., 1996. Simulation des endommagements et de la rupture dans les composites stratifiés, Thesis, Université Pierre et Marie Curie Paris 6/LMT/ENS-Cachan, ISBN 211-088-9705. 